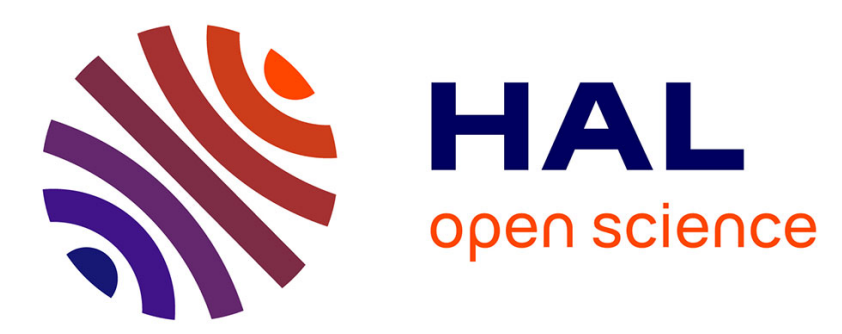

\title{
Experimental investigation of basalt rocks as storage material for high-temperature concentrated solar power plants
}

\author{
Tamar Nahhas, Xavier Py, Najim Sadiki
}

\section{- To cite this version:}

Tamar Nahhas, Xavier Py, Najim Sadiki. Experimental investigation of basalt rocks as storage material for high-temperature concentrated solar power plants. Renewable and Sustainable Energy Reviews, 2019, 110, pp.226 - 235. 10.1016/j.rser.2019.04.060 . hal-03484484

\author{
HAL Id: hal-03484484 \\ https://hal.science/hal-03484484
}

Submitted on 21 Dec 2021

HAL is a multi-disciplinary open access archive for the deposit and dissemination of scientific research documents, whether they are published or not. The documents may come from teaching and research institutions in France or abroad, or from public or private research centers.
L'archive ouverte pluridisciplinaire HAL, est destinée au dépôt et à la diffusion de documents scientifiques de niveau recherche, publiés ou non, émanant des établissements d'enseignement et de recherche français ou étrangers, des laboratoires publics ou privés.

\section{(ㄷ)(1) $\$$}

Distributed under a Creative Commons Attribution - NonCommercial| 4.0 International 


\title{
Field-receiver model validation against Solar Two tests
}

\author{
M.R. Rodríguez-Sánchez ${ }^{1 *}$, A. Sánchez-González ${ }^{1}$, D. Santana ${ }^{1}$ \\ 1 Energy Systems Engineering Group (ISE), Department of Thermal and Fluid Engineering, \\ Universidad Carlos III de Madrid, Av. Universidad, 30, 28911 Leganés, Madrid, Spain \\ *Phone number: +34 916246034, e-mail: mrrsanch@ing.uc3m.es
}

\begin{abstract}
Validation is a crucial aspect in the reliability assessment of models. Validation accuracy is measured with respect to experimental data. In this regard, there is not any experimental technique with sufficient spatial resolution capable of measuring the incident solar flux onto the receiver of solar power tower plants to model validation. Therefore, the individual optical efficiency of the field and the thermal performance of the receiver cannot be accurately obtained experimentally. To calculate these efficiencies, the development of numerical models is mandatory. Although, numerous receiver models can be found in the literature, the accuracy of most of them is not checked because of the scarcity of experimental data to compare with.

In this study, the simulations of a model that includes the heliostat field and an external tubular receiver, taking into account all the receiver tubes, have been compared with available experimental data from Solar Two plant, in order to check its accuracy. It was obtained that the model overestimates $1.42 \%$ the total mass flow rate and $0.73 \%$ the global efficiency of Solar Two, which is almost negligible. Besides, the field-receiver efficiency can be calculated with confidence using Solar Two experimental data, and then it can be taken into account in the validation of the model. The model error, with respect to the experimental data are of $1.1 \%$ at full load and $1.4 \%$ at $50 \%$ partial load.
\end{abstract}

\section{Keywords}

Solar Two; external tubular receiver; optical model; thermodynamic model; validation.

\section{Introduction}

The main issue for new solar tower projects is to confidently forecast the power plant production. In the procedure to assess the reliability of the estimations of the Solar Power Tower (SPT) performance, validation is the crucial step. Validation is the process of determining the degree to which a model is an accurate representation of the real world and the accuracy is a measure with respect to experimental data. Therefore, experimental data, obtained for demonstration and/or industrial scale SPTs, are essential to forecast the performance of new solar tower projects. 
Unfortunately, neither the heliostat-field optical-performance nor the receiver thermalperformance can be obtained experimentally, at least for industrial scale. Such performances cannot be obtained experimentally because of the measurement of the solar flux distribution incident onto the receiver tubes is impracticable. Note that the receiver tube surface ranges from $1000 \mathrm{~m}^{2}$ (Solar Two project [1]) to $3000 \mathrm{~m}^{2}$ (Crescent Dunes project [2]). Nowadays, there is not any fully developed experimental technique capable of measuring the solar distribution intercepted by such huge surface area with an acceptable spatial resolution for both heliostat field and receiver validation purposes. Röger et al. [3] summarized existent techniques that can be applied to large-scale receivers to measure the solar flux density distribution. The most popular technique consists in a direct measurement in which a white diffuse moving bar target, a CCD camera and a flux sensor are used to reconstruct the solar flux distribution on the receiver surface. Depending on the sensor used and the position of the moving bar the accuracy of the methodology varies between $3 \%-9 \%$. In external receivers there are overheating problems on the mobile bar, thus the receiver surface is directly used as a diffuse target in which the reflectivity is characterized increasing the uncertainty up to $20-40 \%$. Current solar plants try to estimate the wall temperature distribution by means of infrared cameras and thermocouples located in the rear part of the tubes, but they only control the existence of hot/cold spots. Besides, there are some experimental data obtained from small scale labs using high flux solar simulators [4] or in which only a small portion of the receiver is studied [5]. In any case, although temperature distributions can be measured at laboratory scale, the incident solar power is a parameter that cannot be measured at any scale with accuracy. Hence, the inability to measure both the incident solar flux and the temperature profile during the SPT operation makes necessary the development of numerical models.

The flux distribution on central receivers is computed with optical tools, which depending on the calculation approach can be classified into two groups: ray tracing and convolution [6]. A large number of rays following sunshape are statistically traced in Monte Carlo Tray Tracing (MCRT) tools such as: MIRVAL [7], SolTrace [8], Tonatiuh [9], Stral [10], Solfast [11], SOLUCAR [12] or SPTOPTIC [13]. Great computation time can be saved with convolution-based models that superpose and convolve the functions of sunshape, concentration and optical errors. Depending on the way the convolution is worked out, existing codes are: UHC a cell model that establishes an array of representative heliostats [14]; DELSOL using Hermite polynomial expansion [15]; HELIOS performing the fast Fourier transform [16]; UNIZAR whose analytic function results from the integration in the image plane [17]; Fiat-Lux that uses a normally distributed random value of slope error [18]; and HFLCAL whose analytic function is directly a 
circular Gaussian distribution [19]. Recently, SolarPILOT integrates both ray tracing and convolution methods based on DESOL and SolTrace tools to analyse more complex geometries [20]. In the present work, it is used FluxSPT software tool that is grounded on the projection to the central receiver panels of the flux distribution in the image plane obtained from an analytic function, UNIZAR in this instance [21].

The quantity of models that solve the receiver thermal behaviour is also abundant, they can be classified in detailed and simplified models. The first category is solved using CFD tools [2230]; while the second category comprises low-detail models between them it is worth highlighting: CAVITY, which solves the energy balance in tubular cavity receivers coupling the radiative exchange to conduction and convection [31]; DRAC and TOPAZ simulate onedimensional fluid flow in pipes with both steady and transient heat and mass transfer [31]; CGM is a simplified 2D model for external tubular receivers, that takes into account circumferential variations of the tube wall temperature, with a grid size equal to the panel width assuming the same behaviour for all the tubes in a panel [32]; FGM is an evolution of the previous model, where the grid size is reduced to the tube diameter and then all the tubes of the receiver are calculated individually [33]; ASTRID code, developed by DLR, comprises a lowdetail model that utilizes a number of simplifications for optimization purposes and a highdetail model based on FEM [34].

The main problem of most of the numerical models is that they handle individually either the solar field or the receiver. Nevertheless, Rodríguez-Sánchez et al. [35] pointed out that both solar field and receiver subsystems have to be studied together to obtain representative results, since they are interrelated, as some aiming strategies pay attention to SánchezGonzález et al. [36]. Some of the most important models that solve the global SPT are [37]: SAM, which is a system-level software that predicts the performance and economics of different concentrated solar power technologies [38], in the case of SPT it is based in the code developed by [39]; SOLERGY simulates the operation and annual power output of SPTs utilizing weather data, including parasitic power requirements of the plant [40]; SOFIA consists of a simulation environment that approaches the analysis of concentrated solar technologies with different quality levels, in the design phase a medium quality model is used for the optical, thermal and electrical calculations, the validation of the optimal designs is carried out with a high quality model, which consists of several modules [41]; Fully-coupled multi-level analytical methodology, that using the models 0-1-2-3 enables both system level-performance prediction and component-level targeting insight [42]. The models that conjugate the different subsystems of the SPT usually reduce the computational cost by means of simplifications, 
which result in temperatures and efficiencies far from the real ones. Hence, although the numerical models could be very useful, the scarcity of experimental data concerning SPTs makes difficult their validation and then its reliability is questioned.

The only data published in literature of real SPTs belong to Solar One project (steam receiver) and Solar Two project (molten salt receiver). Radosevich [43] reported the experimental test results of Solar One SPT, he measured the Direct Normal Irradiation (DNI) and the gross power of the plant. Using those data, he calculated the efficiencies of the global power plant and the power block with confidence. However, the heliostat field and the receiver efficiencies were estimated by means of simulations or using different hypothesis, then these two last data cannot be used for validation purposes. Pacheco [1] documented the experiments carried out in Solar Two SPT, a molten-salt power tower refurbishment of Solar One, at full and partial load. During the experiments the data collected were the mass flow rate, the inlet and outlet temperatures of the heat transfer fluid, the DNI and the wind speed, but there are no measurements regarding the wall temperature, the incident power on the receiver or the optical efficiency of the field.

The main goal of this work is to validate the numerical FluxSPT-FGM developed by $[21,33]$, which englobes the optics of the solar field and the thermal behaviour of the receiver, by means of the experimental tests conducted in Solar Two plant. Firstly, Solar Two plant and the tests carried out on it have been detailed. Secondly, the numerical model, its main assumptions and its input data have been described, to finally validate it with the experimental data collected in Solar Two plant: mass flow rate and global SPT efficiency.

\section{Solar Two SPT}

\subsection{Plant description}

Solar Two was a demonstration plant using molten salt as heat transfer fluid, which was operated during the late 90s. Solar Two tower was $76.2 \mathrm{~m}$ high, with an external tubular receiver arranged in its top. The receiver consisted of panels with headers and arranged metallic tubes, which are coated with a selective paint. The panels were mounted vertically, shaping a cylinder-like receiver. The heat transfer fluid flowed throughout two independent circuits, whose inlet was in the North side and the outlet in the South side, with a crossover in their middle length. The solar field of Solar Two consisted of 1818 heliostats of $39.13 \mathrm{~m}^{2}$ plus 108 heliostats of $95 \mathrm{~m}^{2}$ arranged around the tower, whose coordinates were collected in Pacheco [1]. The main geometrical parameters of the plant are summarized in Table 1. 
Table 1. Main design parameters of the Solar Two heliostat field and solar receiver [1].

\begin{tabular}{ll}
\hline Number of Heliostats & 1926 \\
Heat Transfer Fluid & Molten Salt \\
Tube material & $316 \mathrm{H}$ Stainless Steel \\
Receiver Diameter/ Height & $5.1 / 6.2 \mathrm{~m}$ \\
Inlet/ Outlet temperature & $290 / 565^{\circ} \mathrm{C}$ \\
Number of flow circuits & 2 \\
Number of panels & 24 \\
Number of tubes per panel & 32 \\
Tube diameter/thickness & $21 / 1.2 \mathrm{~mm}$ \\
Absorptivity $(\boldsymbol{\alpha})$ & 0.95 (Black Pyromark) \\
\hline
\end{tabular}

\subsection{Experimental tests}

During 9 clear-sunny days four different tests were performed symmetrically about solar noon between 11:00 a.m. and 1:00 p.m. solar time. In the different periods of time, all the heliostats of the field (full power: cases $A$ and $C$ ) or half of them scattered around the receiver (half power: cases $B$ and $D$ ), were under operation, see Table 2 for further information.

Table 2: Sequence of heliostat tracking the receiver [1].

\begin{tabular}{cccc}
\hline Period & Solar Time & $\begin{array}{c}\text { Heliostat } \\
\text { Group(s) }\end{array}$ & $\begin{array}{c}\text { Incident Power } \\
\text { (Available) }\end{array}$ \\
\hline A & 11 a.m. to 11:30 a.m. & 1 and 2 & $100 \%$ \\
B & $11: 30$ a.m. to 12 p.m. & 1 & $50 \%$ \\
C & 12 p.m. to 12:30 p.m. & 1 and 2 & $100 \%$ \\
D & 12:30 p.m. to 1 p.m. & 2 & $50 \%$ \\
\hline
\end{tabular}

The experimental data collected in Pacheco [1] during each test were: field availability, mass flow rate at the receiver, inlet and outlet temperature of the salt, DNI, and wind direction and speed, see Table 3 . The heliostat reflectivity, cleanliness, tracking error and field availability were also gathered. Finally, the gross electrical output in steady-state was measured, being 1 to $8 \mathrm{MWe}$ at partial load and 9 to $12 \mathrm{MWe}$ at full load.

Table 3: Summary of key measurements during receiver efficiency tests [1].

\begin{tabular}{|c|c|c|c|c|c|c|c|c|c|}
\hline Test Date: & $\begin{array}{l}\text { ลे } \\
\text { ภे } \\
\text { ᄋે }\end{array}$ & $\begin{array}{l}\text { बे } \\
\text { के } \\
\text { ᄋे }\end{array}$ & $\begin{array}{l}\text { مे } \\
\text { ᄋે- } \\
\stackrel{-}{\circ}\end{array}$ & 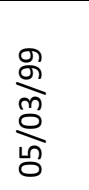 & 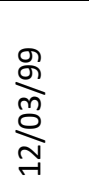 & $\begin{array}{l}\text { g } \\
\text { ñ } \\
\text { ㄱ }\end{array}$ & $\begin{array}{l}\frac{\text { g }}{\text { ñ }} \\
\stackrel{\text { N }}{\text { N }}\end{array}$ & 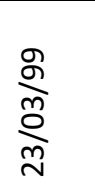 & 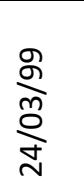 \\
\hline \multicolumn{10}{|c|}{ Heliostats Tracking Receiver } \\
\hline$A$ & 1767 & 1764 & 1804 & 1668 & 1685 & 1681 & 1699 & 1626 & 1725 \\
\hline B & 883 & 883 & 897 & 831 & 853 & 836 & 847 & 809 & 858 \\
\hline C & 1767 & 1758 & 1798 & 1664 & 1684 & 1676 & 1692 & 1625 & 1720 \\
\hline $\mathrm{D}$ & 884 & 876 & 898 & 833 & 830 & 840 & 847 & 805 & 848 \\
\hline \multicolumn{10}{|c|}{ Average Mass Flow $(\dot{\eta})[\mathrm{kg} / \mathrm{s}]$} \\
\hline $\mathrm{A}$ & 80 & 90 & 90 & 81 & 67 & 78 & 69 & 61 & 70 \\
\hline B & 39 & 43 & 44 & 36 & 32 & 37 & 32 & 28 & 33 \\
\hline
\end{tabular}




\begin{tabular}{llllllllll}
\multicolumn{1}{c}{$\mathrm{C}$} & 85 & 91 & 91 & 80 & 73 & 80 & 70 & 65 & 73 \\
\multicolumn{1}{c}{$\mathrm{D}$} & 39 & 43 & 42 & 38 & 33 & 36 & 32 & 30 & 32 \\
\hline $\begin{array}{l}\text { Average Inlet } \\
\left.\text { Temperature [ }{ }^{\circ} \mathrm{C}\right]\end{array}$ & 295 & 301 & 305 & 308 & 303 & 302 & 301 & 302 & 299 \\
\hline $\begin{array}{l}\text { Average Outlet } \\
\text { Temperature [으 }\end{array}$ & 551 & 550 & 550 & 564 & 563 & 564 & 563 & 561 & 564 \\
\hline $\begin{array}{l}\text { Average Ambient } \\
\left.\text { Temperature [ }{ }^{\circ} \mathrm{C}\right]\end{array}$ & 32 & 33 & 33 & 16 & 14 & 18 & 18 & 16 & 17 \\
\hline $\begin{array}{l}\text { Average Direct Normal } \\
\text { Insolation [W/m }{ }^{2} \text { ] }\end{array}$ & 913 & 975 & 942 & 989 & 898 & 960 & 871 & 874 & 894 \\
\hline $\begin{array}{l}\text { Average wind speed } \\
\text { [m/s] }\end{array}$ & 0.6 & 1 & 0.6 & 3 & 1.8 & 1.4 & 0.9 & 7.9 & 1.3 \\
\hline $\begin{array}{l}\text { Average wind direction } \\
\text { (Clockwise from North) }\end{array}$ & 131 & 241 & 210 & 270 & 223 & 241 & 165 & 263 & 241 \\
\hline
\end{tabular}

To calculate the global efficiency of the power plant $\left(\eta_{S P T}\right)$ it is required to know the efficiency of the three main subsystems: solar field $\left(\eta_{\text {opt }}\right)$, receiver $\left(\eta_{r}\right)$ and power block $\left(\eta_{p b}\right)$, see Equation 1 [1]. Itemizing each term, it is obtained that the global efficiency of the plant is function of known variables: the DNI, the total surface of mirrors on the field $\left(A_{H}\right)$ and the gross electrical output $(W)$ and then it can be calculated with confidence from the experimental data, see Equation 2. Note that $\eta_{p b}$ takes into account the mechanical to electrical conversion and that $\eta_{\text {opt }}$ also considers the reflectivity and the cleanliness of the heliostats.

$$
\begin{gathered}
\eta_{S P T}=\eta_{o p t} \eta_{r} \eta_{p b} \\
\eta_{S P T}=\frac{P_{I N C}}{D N I \cdot A_{H}} \cdot \frac{P_{A B S}}{P_{I N C}} \cdot \frac{W}{P_{A B S}}=\frac{W}{D N I \cdot A_{H}}
\end{gathered}
$$




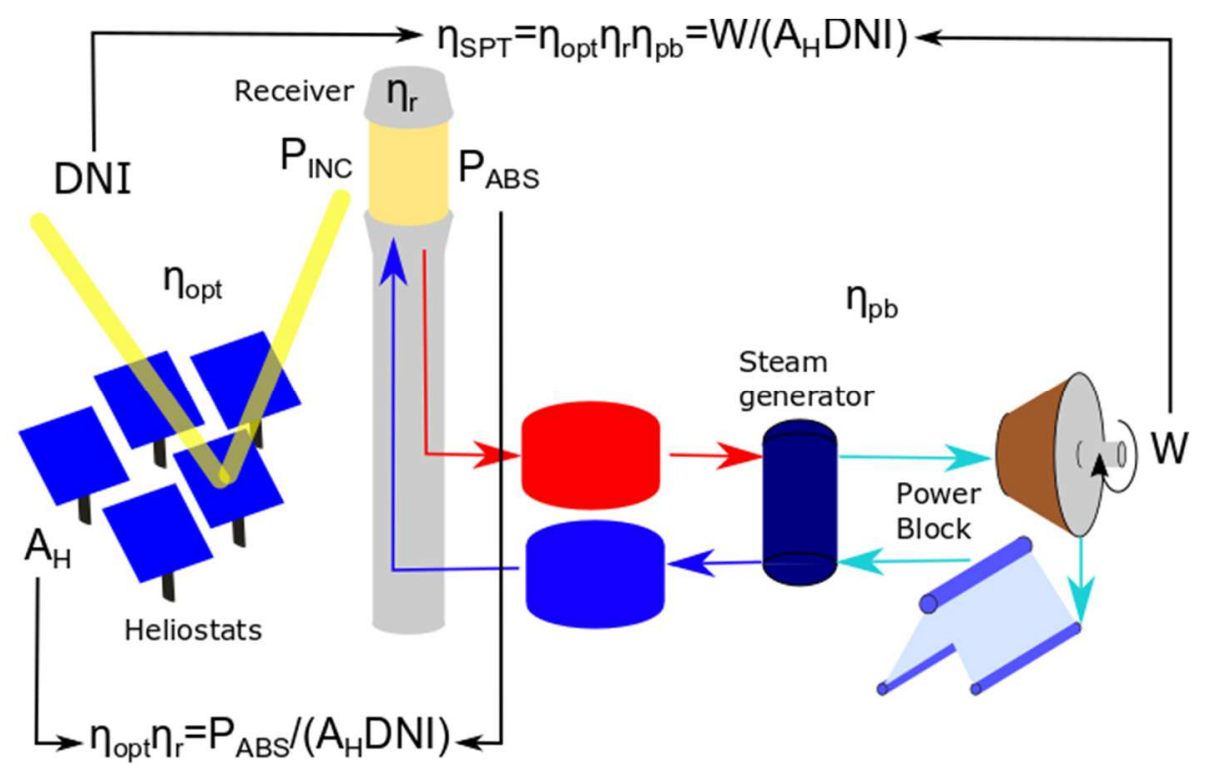

Figure 1 - Schematic of the solar power tower

The thermal power absorbed by the heat transfer fluid in the receiver $\left(P_{A B S}\right)$ can also be easily estimated with an energy balance, see Equation 3. Being $\Delta T$ the salt temperature increment and $C_{P}$ the specific heat. The incident power $\left(P_{I N C}\right)$ is not a measurable data, which makes impossible the calculation of the individual efficiencies of the solar field and the receiver separately, without the development of physical models. Nevertheless, both efficiencies can be calculated together, see Equation 4.

$$
\begin{gathered}
P_{A B S}=\dot{m}_{\text {salt }} C_{P} \Delta T_{\text {salt }} \\
\eta_{\text {opt }} \eta_{r}=\frac{P_{I N C}}{D N I \cdot A_{H}} \cdot \frac{P_{A B S}}{P_{I N C}}=\frac{P_{A B S}}{D N I \cdot A_{H}}
\end{gathered}
$$

The steady-state gross conversion efficiency of the Solar Two power block was calculated in Pacheco [1] to be $34.1 \%$ at full load, $33.8 \%$ at $84 \%$ load, $32 \%$ at $57 \%$ load and $23.3 \%$ at $22 \%$ load. Using the obtained gross electricity output, the solar insolation and the solar field surface, the global efficiency of the power plant at full power was 15\% (Equation 2). Note that the parasitic consumptions of the SPT have not been taken into account for this calculation. Therefore, at full load the combined field-receiver efficiency must be around $44 \%$.

The rest of parameters of the plant, as $P_{I N C}$, cannot be calculated with confidence and the development of models is required. To avoid developing a thermal model of the receiver, Pacheco implemented the Power-On Method (POM) to calculate the thermal efficiency of the receiver. POM assumes that the incident power at full load is twice the incident power at $50 \%$ 
partial load and that the wall temperature distribution and the thermal losses $\left(\bar{L}_{h h}\right)$ are the same, independently of the incident power, hence [1]:

$$
\begin{gathered}
P_{I N C}=\frac{P_{A B S}+\bar{L}_{t h}}{\alpha} \\
\bar{L}_{t h}=\frac{1}{2}\left(P_{A B S, A}+P_{A B S, C}-2 P_{A B S, D}-2 P_{A B S, C}\right)
\end{gathered}
$$

POM method requires to carry out experiments at least at two different power loads, to obtain the incident power and then the receiver efficiency. With the tests conducted in Solar Two Pacheco obtained an $88 \%$ of receiver efficiency at full load. Concurrently, Pacheco used RCELL [14] and SOLERGY [40] optical codes to study the solar field behaviour, obtaining a $63 \%$ of optical efficiency at full load. This gave $55.4 \%$ of combined field-receiver efficiency, roughly 10 percentage points extra than the value expected and $19 \%$ of global SPT efficiency instead of 15\%. To solve this problem, Pacheco deployed the incident power obtained with POM, with these values the optical efficiency of the solar field was deduced, resulting in a $57 \%$ for full load. This way the miscalculation was reduced, getting a $50 \%$ of combined field-receiver efficiency (6 percentage points higher than the measured value) and $17 \%$ of global SPT efficiency ( 2 percentage points higher than the measured value). Although, these values are closer to the real plant efficiency (15\%), this methodology is not totally accurate and even less for partial load.

The miscalculation of POM are due to both initial hypotheses. Firstly, the wall temperature distribution and the thermal losses vary with the incident power level since the Biot number is of order unity, as was seen in Rodríguez-Sánchez et al. [44]. Furthermore, Rodríguez-Sánchez et al. [35] pointed out that the wall temperature distribution and the thermal losses depend on both power level and power distribution. Hence, as POM is not only based in the Solar Two experimental data it should be avoided for validation purposes. Secondly, the incident power at full load is not exactly twice the incident power at $50 \%$ partial load because the DNI varies from one test to the next.

\subsection{Experimental uncertainties}

The experimental tests carried out in Solar Two have several uncertainties associated to the operation of the plant. Some of them were not described in detail and other were difficult to characterize in the real plant. The most important uncertainties have been described below: 
- The measured data were given as the averages for periods of 30 minutes. Thus, only one representative instant of time can be characterized when the data are analysed.

- The aiming strategy in Solar Two has not been described in detail. It can be assumed that it is homogeneous and with low spillage losses, but it could have a variability with respect to the real one.

- The availability of the solar field was given with the number of heliostats aiming to the receiver. However, Solar Two has two heliostat sizes and the number of heliostat of each type that were working on each experimental test was not specified. It could slightly modify the power intercepted by the field.

- The reflectivity and cleanliness of the mirrors should be different for each heliostat. Nevertheless, Pacheco [1] gave them for four different sectors of the field. The error relative to this effect can be neglected.

- There is a deterioration of the optical properties of the coating and the tubes under receiver operation during its lifetime. As this deterioration is difficult to quantify, the optical properties can be considered ideal and constant.

- The distribution of the heat transfer fluid flow in the receiver were not clearly described. It is unknown if the average outlet temperature corresponds to the average between both flow circuits or if it is reached individually in each circuit. But taking into account that data were gathered close to solar noon, the incident solar flux and the mass flow rate of each flow path should be equivalent.

- There is no information about the circuit that connects two adjacent panels. Usually they are placed inside ovens to reduce the heat losses, then the process can be supposed adiabatic with low margin of error.

\section{Modelling}

Solar field and receiver subsystems are interrelated and they should be evaluated together to obtain representative results with confidence [35]. Therefore, in this study the optical model FluxSPT [21] and the receiver thermal Fine Grid Model (FGM) [33] have been combined to obtain the field-receiver efficiency of Solar Two power plant.

\subsection{Optical model}

The heliostat field model FluxSPT [21] has been used to simulate the solar flux intercepted by Solar Two receiver. This model computes the flux distribution on the image plane by every single heliostat and projects the distribution into the panels of any central receiver in SPTs (oblique mapping). The model allows using different aiming strategies from equatorial to 
flattest flux distribution. FluxSPT has been validated with PSA [45] and Thèmis [46] measurements.

The aiming strategy during Solar Two experimental tests has not been reported in detail, however Pacheco claimed that the heliostats were aimed at different positions along the vertical of the receiver surface [1]. Each heliostat target point was set every 10 minutes by the Static Aim Processing System (SAPS), which provided a "smart" aiming to minimize the spillage losses for a desired flux distribution, while the Dynamic Aim Processing System (DAPS) protected the receiver from incident fluxes over $850 \mathrm{~kW} / \mathrm{m}^{2}$.

In a previous research Rodríguez-Sánchez et al. [44] used a fairly homogeneous solar flux distribution for Solar Two, which is less aggressive for the receiver. It was obtained using a multi-aiming strategy with FluxSPT, selecting an aiming factor equal to 1.5. The aiming factor, $k$, is defined to have values from 0 to 3 and gives an idea on the energy intercepted by the receiver, in line with the 68-95-99.7 rule for the normal distribution. From that aiming strategy, the resulting spillage loss was $28.60 \%$ on average.

In Sánchez-González et al. [21] the methodology to obtain the flattest flux profiles was described. It consists in dividing the field in the same number of sectors as panels in the receiver. All the heliostats of each field sector focus the receiver using the same aiming factor. The aim point of each heliostat is the one that makes the beam radius, as a function of $k$, tangent to the bottom/top edge of the receiver. When the beam size is higher than the receiver height, the heliostat aims to the equatorial belt of the receiver. The $k$ value that flattens the vertical flux profiles is the chosen for each field sector. With this methodology the average spillage loss is reduced to $28.28 \%$. Because of the slight reduction in the spillage loss compared to the previous research, the flux maps obtained with both aiming strategies are almost equivalent.

Figure 2 shows the individual efficiency of each heliostat of the field for the four cases analysed during the $29 / 09 / 97$, using the flat aiming strategy. Note that the grey points in cases $B$ and D (50\% partial load) correspond to non-tracking heliostats. It can be seen that before solar noon, the maximum efficiencies are slightly displaced to the north-west of the field (top right side of the figure) and that after solar noon they are slightly displaced to the north-east sector of the field, consistently with sun movement. In Figure 2 can be seen the optical efficiency of the whole solar field for each case, which corresponds to 9 percentage points lower than that obtained with RCELL model. It is worth noting that all sources of heliostat optical loss are herein considered, including heliostats reflectivity $(\rho)$, cleanliness $(c l)$, 
atmospheric attenuation $\left(\eta_{a t}\right)$, shadowing and blocking $\left(\eta_{s \& b}\right)$ and spillage $\left(\eta_{s p}\right)$, for further information of each parameter calculation refer to [45]:

$$
\eta_{o p t}=\rho \cdot c l \cdot \cos (\beta) \cdot \eta_{a t} \cdot \eta_{s \& b} \cdot \eta_{s p}
$$

A

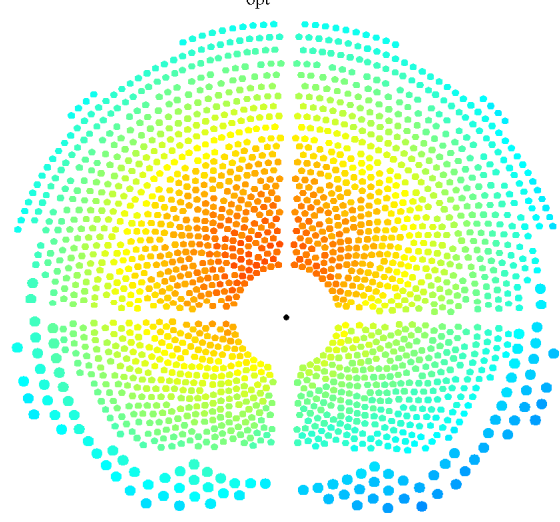

$\mathrm{C}$

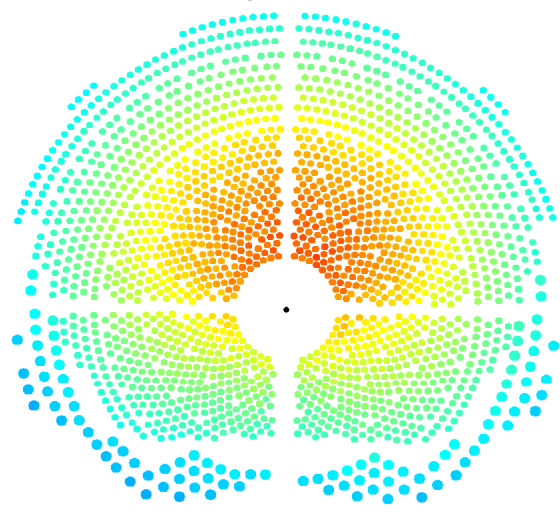

B

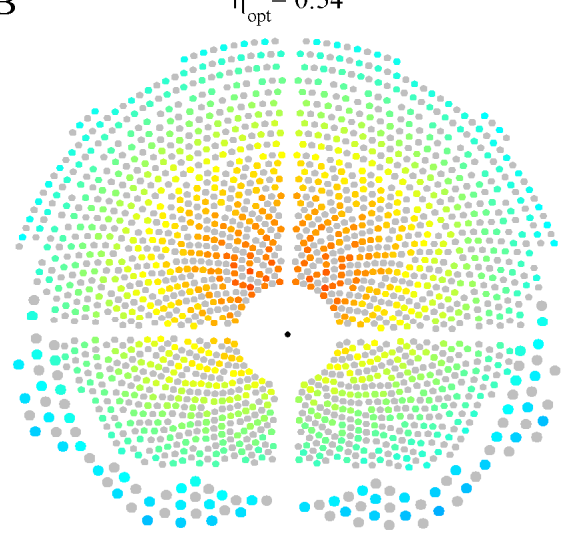

$\mathrm{D}$

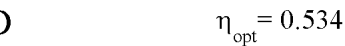

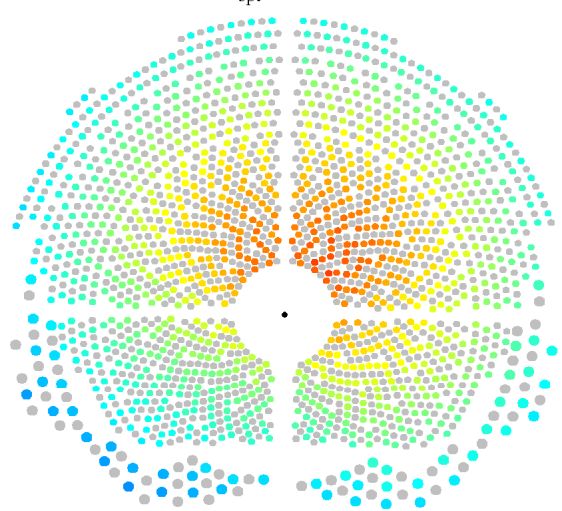

Optical efficiency

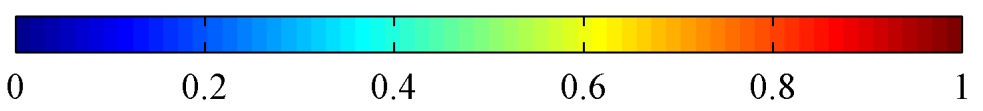

Figure 2 - Optical efficiency of the field for the four cases carried out during the 29/09/97 (including heliostat reflectivity and cleanliness).

Once the aiming strategy that flattens the incident flux on the receiver has been selected the optical model computes the concentration ratio $(C)$ on the receiver surface, from which the flux density $(F)$ distribution on the receiver is obtained as $F=D N I \cdot C$, see Figure 3 . Note that these flux maps correspond to the efficiencies shown in Figure 2. Symbol $E$ represents the eastern receiver side and symbol $W$ the western receiver side, while the number close to the symbols indicates the panel number in each flow circuit, starting in the north, which is the inlet of the paths $(x=0 \mathrm{~m})$. The incident solar flux is quite homogeneous and it is up to $300 \mathrm{~kW} / \mathrm{m}^{2}$ higher in cases $A$ and $C$ (full load) than in B and D ( $50 \%$ partial load). The effect of the sun 
movement with respect to the solar noon can be clearly observed in the displacement of the solar peak flux on the receiver.

A
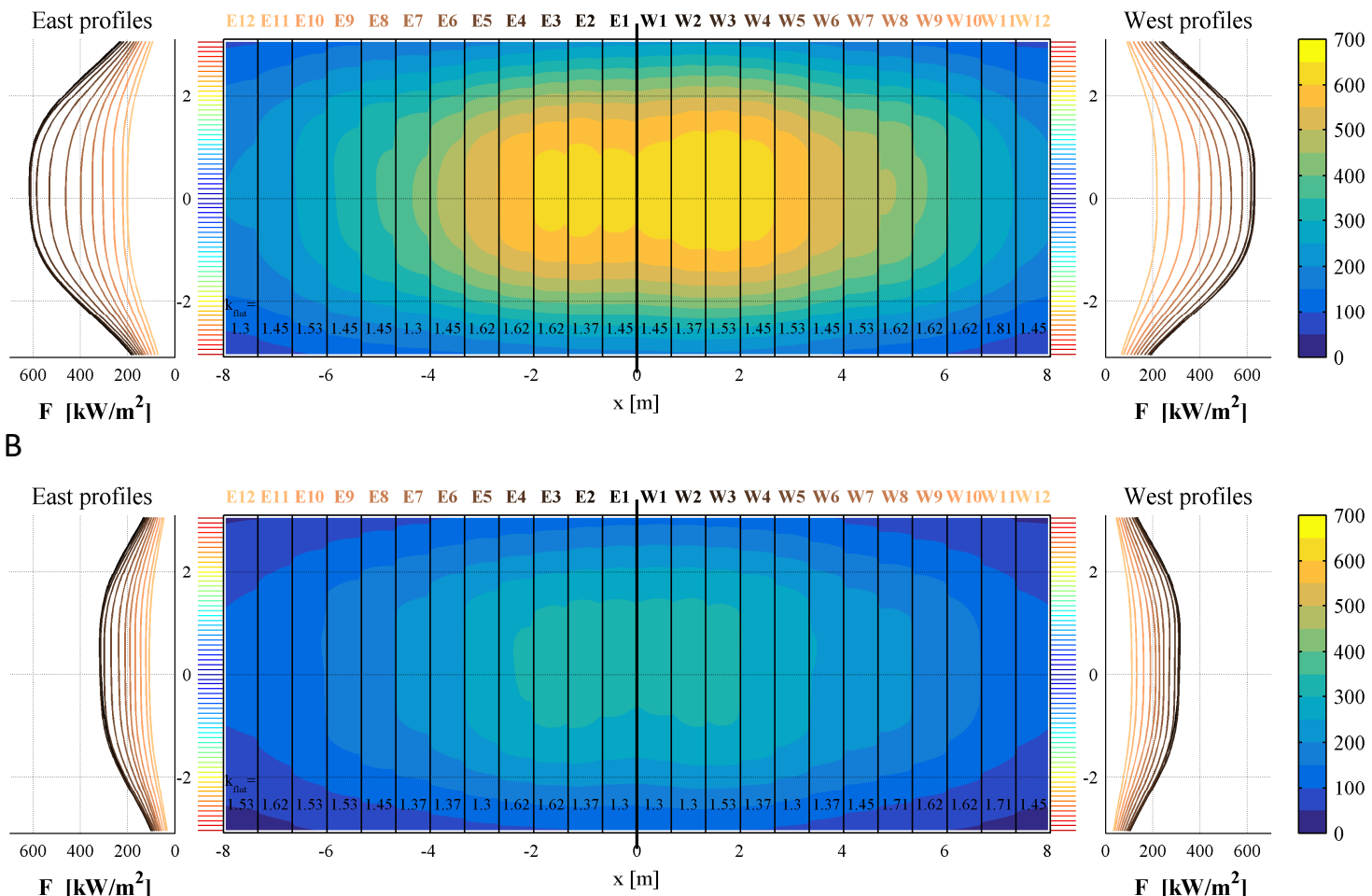

C

$\mathrm{F}\left[\mathrm{kW} / \mathrm{m}^{2}\right]$

$\mathbf{F}\left[\mathbf{k W} / \mathbf{m}^{2}\right]$
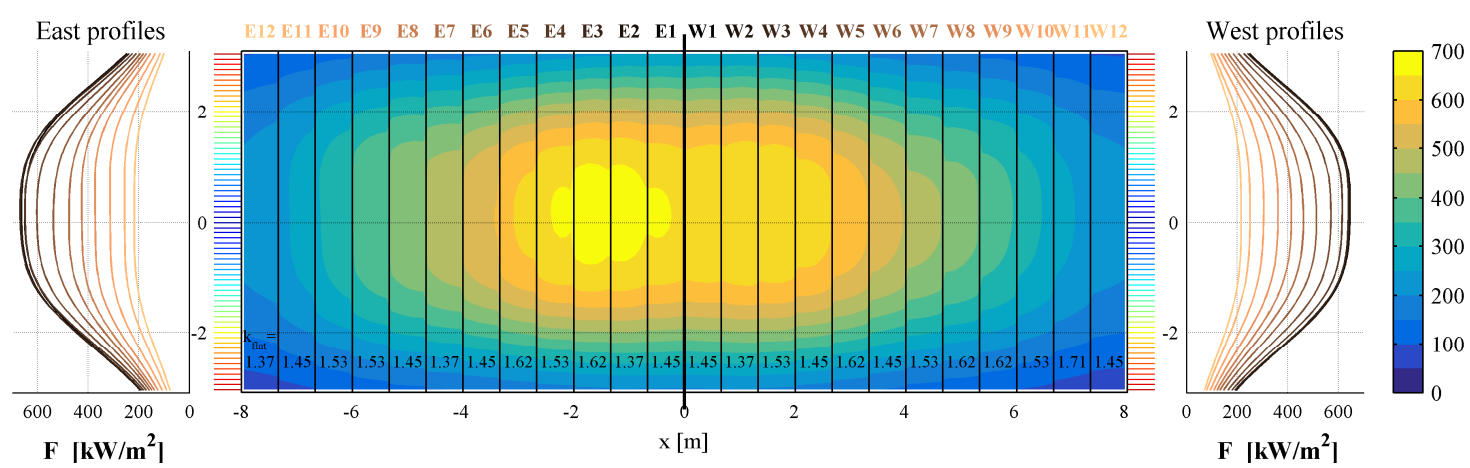

D
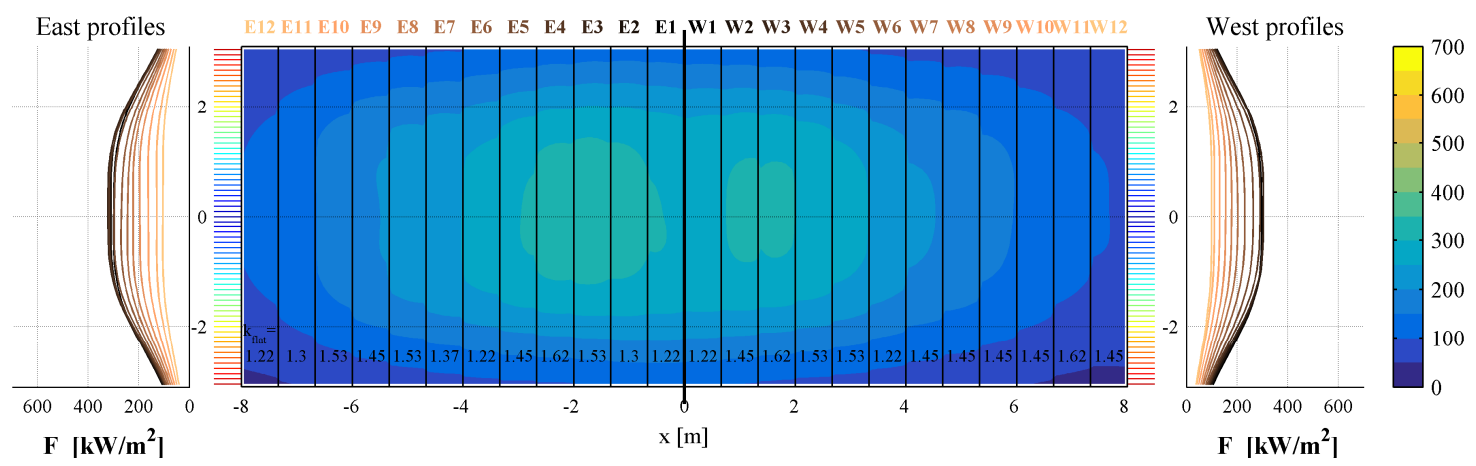

Figure 3: Uniform flux maps on the receiver with $k_{F L A T}$ for the different sectors of the field for the four cases analysed during 29/09/97.

\subsection{Receiver thermal model}


The receiver thermal model developed in Rodríguez-Sánchez et al. [33] has been adapted to Solar Two geometry for validation purposes. This Fine Grid Model (FGM) has a grid size equivalent to the tube diameter plus the separation between tubes, then it obtains the temperature distribution of all the tubes in the receiver. FGM set all the values that appear in Table 3 as inputs, with the exception of the mass flow rate, which is a dependent variable that is obtained as output. The FGM follows an iterative process to calculate the heat transfer, the temperatures involved and the mass flow rate by means of energy balances, which considers the radiative, convective and conductive heat transfer. To do that the cell of calculation includes opposite tubes, an imaginary frontal surface, that represents the sky as well as the ground (i.e. the surroundings), and a real rear surface formed by a highly reflective refractory wall (RW) that is installed to reduce the thermal losses; when the model solves the first or the last tube of a panel the adjacent half tubes of the previous or the following panels have to be considered, see Figure 4. Besides, the FGM meshes each tube of a panel in axial segments and circumferential sections. Hence, all the variables of the tubes depend on the panel, the tube, the axial length and the circumferential position $(p, t, \bar{z}, \theta)$.

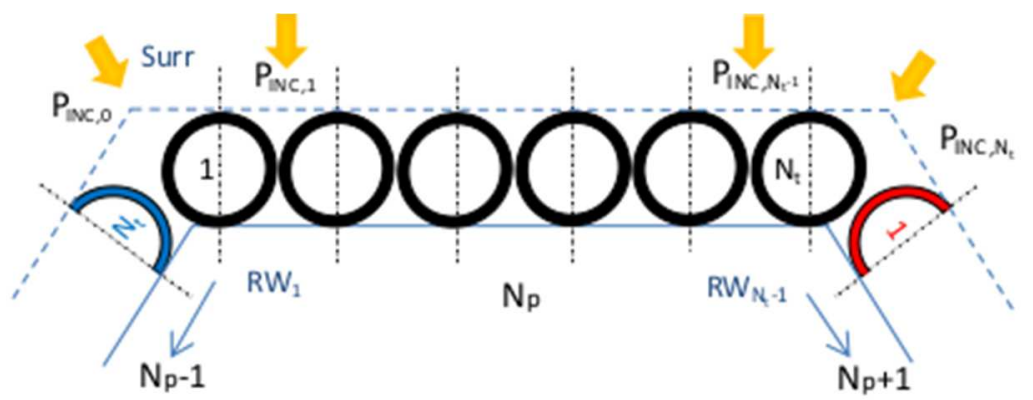

Figure 4: Schematic representation of the basic cell used in the FGM for the panel Np of the receiver. In the FGM the mass flow rate in each flow path is matching, to fulfil the outlet temperature of the salt (see Equation 3). Furthermore, the mass flow rates along all the tubes of a panel are assumed to be the same, given that the pressure drop difference between tubes is negligible. Since wind speed of Table 3 was measured at $10 \mathrm{~m}$ above the ground level, and as the receiver is $76 \mathrm{~m}$ above the ground the correction proposed by Pacheco [1] was applied.

Figure 5 shows the calculation diagram of the combined FluxSPT-FGM for Solar Two. Once the ambient conditions, the field layout and the receiver geometry are known FluxSPT model computes the concentration ratio of the field for an equatorial aiming strategy. Applying a correction for each heliostat the concentration ratio for different aiming factors, $k$, is easily calculated to obtain $k_{\text {flat. }}$. It allows to estimate the solar flux distribution on the receiver surface and the optical efficiency of the field. The obtained solar flux distribution is used as inlet data 
in the FGM that together an initial estimation of the mass flow rate and the wall temperatures computes the heat losses and the heat absorbed by the salt for the first slice (in z direction) of the tubes at the first panel, $N_{z}=1$. Once the wall temperature converges the following $z$ slice is calculated. At the end of the receiver the outlet temperature of the salt is checked, if it is not the expected the mass flow rate is modified and FGM recalculates the whole receiver else the receiver thermal efficiency is estimated and the data can be post-processed.

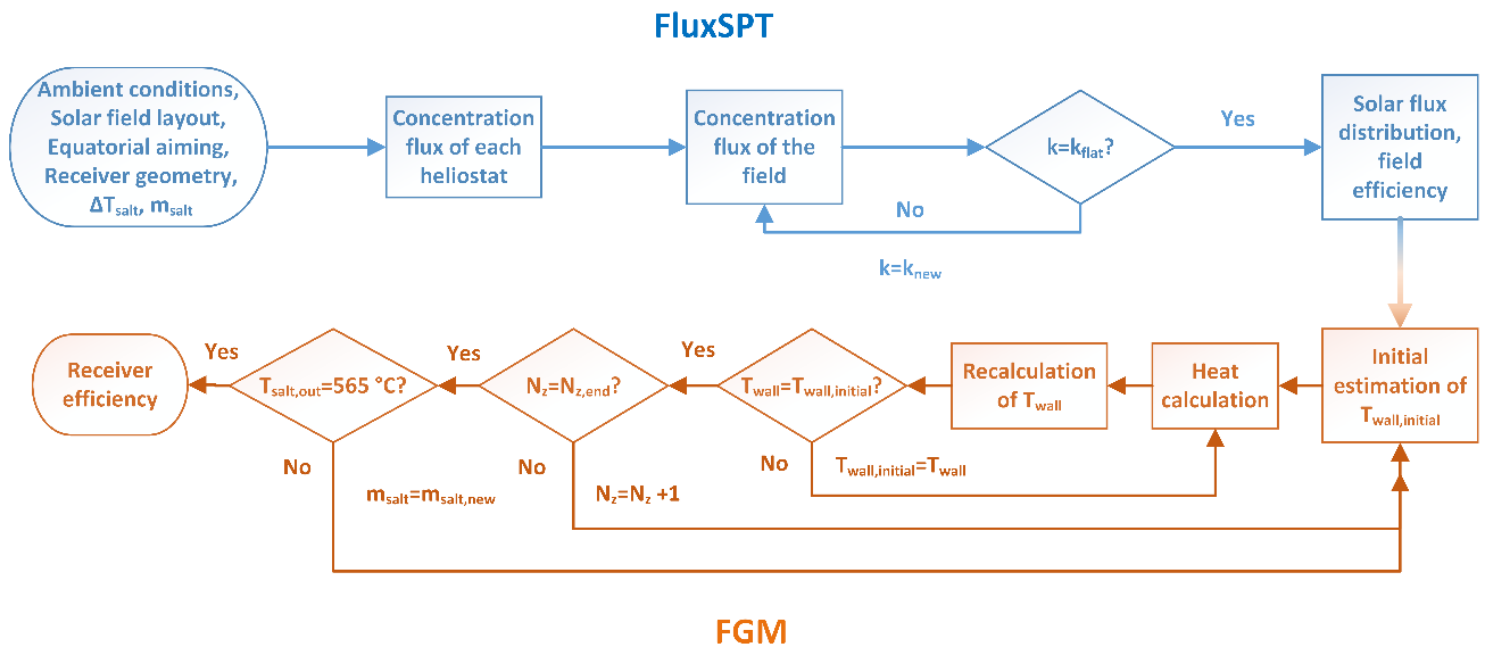

Figure 5: Schematic of calculation of FluxSPT-FGM

\section{Model validation}

The mass flow rate, the global efficiency of the SPT and the combined field-receiver efficiency are the only reliable parameters obtained during the experimental tests that can be used to validate the FluxSPT-FGM. Figure 6 shows the mass flow rate difference between the model presented in this study and the experimental data measured in Pacheco [1]. The differences between the experimental data and the FluxSPT-FGM are comprised between $0.17 \mathrm{~kg} / \mathrm{s}$ and $5.45 \mathrm{~kg} / \mathrm{s}$, being the average difference $1.58 \mathrm{~kg} / \mathrm{s}$. It means that the average mass flow rate difference with the experimental data has been reduced $8.5 \mathrm{~kg} / \mathrm{s}$ with respect to a previous study, in which all the tubes of a panel were assumed to have the same temperature distribution [44]. Taking a nominal mass flow rate of $90 \mathrm{~kg} / \mathrm{s}$, the maximum difference is $6 \%$ and the average $1.76 \%$, calculated as the difference of simulated and measured mass flow rates over the nominal value. 


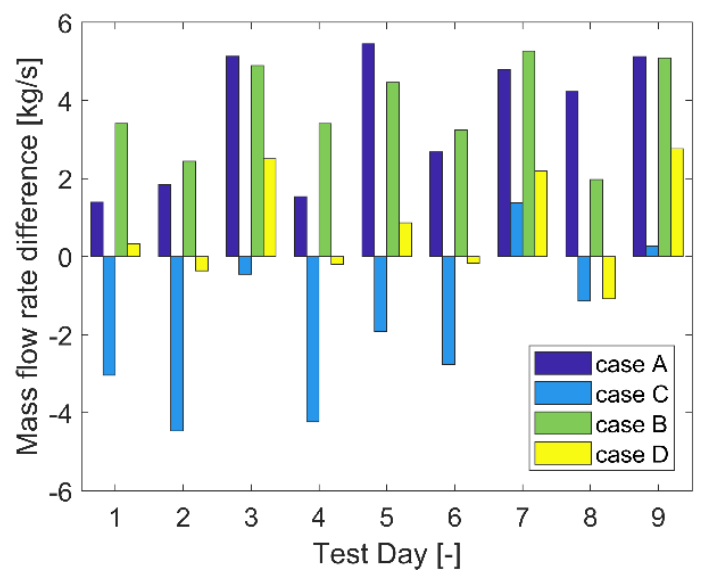

Figure 6: Mass flow rate difference between the experimental data and the FluxSPT-FGM.

The power absorbed by the salt is proportional to the mass flow rate and the salt temperature increment, which is imposed in Table 3. Thus, variations in the absorbed energy respect to the data reported by Pacheco [1] are also negligible.

The global efficiency of the solar power plant was calculated with confidence from the experimental data (Equation 2). Then, in Figure 7 the calculated efficiencies have been compared with the results obtained from the FluxSPT-FGM model. A $34.1 \%$ of power block efficiency has been assumed for this subsystem working at full load (F.L.) and 32\% working at 50\% load (P.L.) [1]. On average, using FluxSPT-FGM we obtain $15.73 \%$ of efficiency for full load, which is pretty close to the $15 \%$ expected. Whereas, for $50 \%$ partial load the global efficiency slightly decreases up to $14.19 \%$.

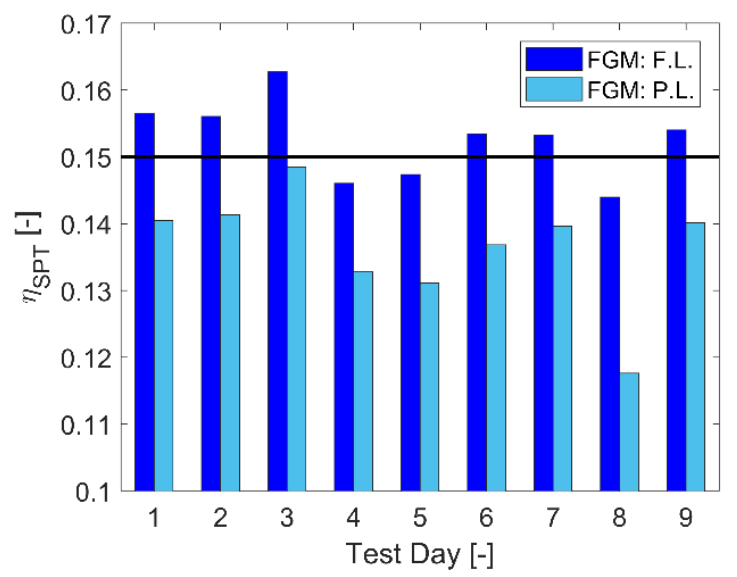

Figure 7: Global efficiency of the solar power plant for full (F.L.) and 50\% partial load (P.L.). The solid black line represents the average measured global efficiency of the SPT.

Considering the field and receiver subsystems, the computed combined efficiency at full load is $46.12 \%$, only a 1.1 percentage points higher than the real value. While at $50 \%$ partial load the FluxSPT-FGM overestimates the combined efficiency in 1.4 percentage points, see Table 4. 
Table 4: Average combined field-receiver efficiencies measured in Solar Two and calculated using the FluxSPT-FGM for the different cases analysed.

\begin{tabular}{ccc}
\hline Case & $\begin{array}{c}\text { Experimental [1] } \\
\eta_{\text {opt }} \eta_{r}[\%]\end{array}$ & $\begin{array}{c}\text { FluxSPT-FGM } \\
\eta_{\text {opt }} \eta_{r}[\%]\end{array}$ \\
\hline $\mathrm{A}$ & 44.61 & 47.36 \\
\hline $\mathrm{B}$ & 44.57 & 46.01 \\
\hline $\mathrm{C}$ & 45.44 & 44.89 \\
\hline $\mathrm{D}$ & 41.30 & 42.65 \\
\hline
\end{tabular}

As the incident power is involved in the efficiencies calculations, it can be assumed that its estimation is pretty accurate, and then both the optical efficiency and the receiver efficiency can be calculated separately with confidence, see Table 5 .

Table 5: Average individual efficiencies of the field and the receiver simulated using the FluxSPT-FGM for the different cases analysed.

\begin{tabular}{ccc}
\hline Case & $\begin{array}{c}\text { FluxSPT } \\
\eta_{\text {opt }}[\%]\end{array}$ & FGM \\
& 52.35 & 90.48 \\
\hline $\mathrm{A}$ & 52.45 & 87.73 \\
\hline $\mathrm{B}$ & 52.66 & 85.24 \\
\hline $\mathrm{C}$ & 51.87 & 82.23 \\
\hline $\mathrm{D}$ &
\end{tabular}

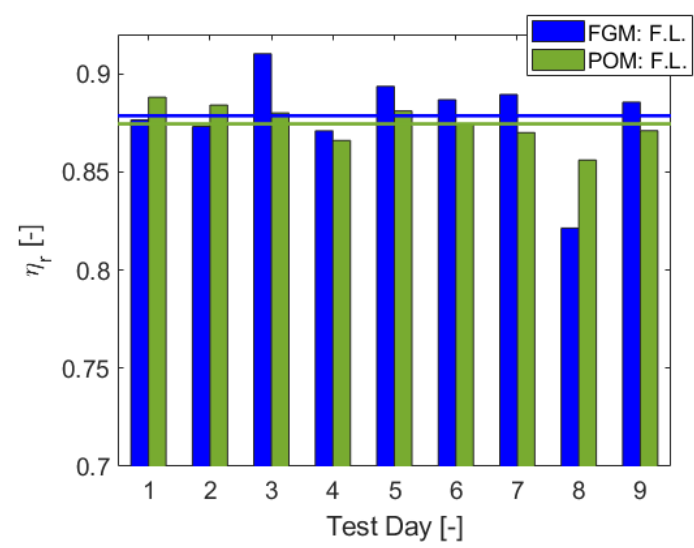

(a)

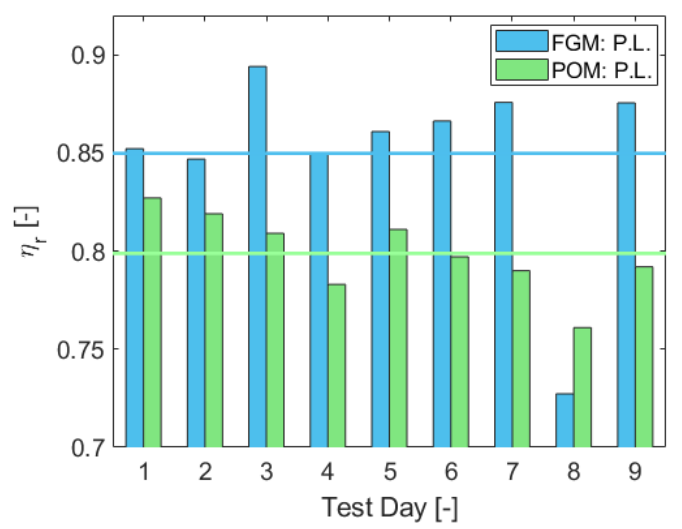

(b)

Figure 8: Receiver thermal efficiency calculated with the FluxSPT-FGM and the POM for (a) full and (b) $50 \%$ partial load.

The data shown in Figure 8 point a good agreement with POM in the calculation of the receiver efficiency at full load, with a deviation of only 0.42 percentage points. However, at $50 \%$ partial load the deviation increases up to 5.18 percentage points. This result was expected, due to the assumption of no thermal losses variations regardless of the load in the POM.

Similar receiver thermal efficiencies were obtained when German Aerospace Center (DLR) validated the tubular receiver model ASTRID ( ) with Solar Two experimental data at full load 
[29,34]. However, as it was pointed in Rodríguez-Sánchez et al. [33], the CGM validated in Rodríguez-Sánchez et al. [44], is unable to predict the individual receiver efficiency with accuracy for any load, obtaining thermal efficiencies up to $10 \%$ percentage points lower than the other models mentioned.

\section{Conclusions}

In absence of experimental techniques to experimentally measure the solar flux distribution on the receiver surface, the development of models to predict the behaviour of the SPTs is required. However, these models are not useful if their accuracy and reliability are not previously validated. In this work, the FluxSPT-FGM developed in $[21,33]$ has been validated with the experimental data available from the report of the Solar Two project at demonstration scale [1].

Using a flat incident solar flux distribution, the results of the numerical model differ $1.76 \%$ in the experimental mass flow rate of heat transfer fluid and 0.73 percentage points in the experimental global efficiency of the power plant.

As in the FGM the mass flow rate and the global SPT efficiency are obtained from an energy balance in which the incident solar flux, the power absorbed by the heat transfer fluid and the tube wall temperature are involved, it can be assumed that all of them can be calculated with confidence when this model is employed. Therefore, it is also possible to calculate separately the optical efficiency of the field and the receiver efficiency. The solar field efficiency from FluxSPT is 9 percentage points lower than that predicted by RCELL and 3 points lower than that obtained with POM at full load.

At full load the receiver efficiency calculated with FGM only differs 0.42 percentage points with respect to POM model, but it increases up to 5.18 percentage points at $50 \%$ partial load. These differences increase at partial loads due to the assumption of constant thermal losses with the incident power made in the POM.

\section{Acknowledgements}

This work has been supported by the Spanish government under the projects ENE2015-69486$R$ (MINECO/FEDER, UE) and by the fellowship "Ayuda a la investigación en energía y medio ambiente" of the Fundación Iberdrola España.

\section{References}


[1] Pacheco JE. Final Test and Evaluation Results from the Solar Two Project. Albuquerque, SAND2002-0120: 2002.

[2] NREL. NREL: National Renewable Energy Laboratory. Http://WwwNrelGov/Csp/Solarpaces/By_projectCfm 2011. http://www.nrel.gov/csp/solarpaces/by_project.cfm (accessed July 2, 2015).

[3] Röger M, Herrmann P, Ulmer S, Ebert M, Prahl C, Göhring F. Techniques to Measure Solar Flux Density Distribution on Large-Scale Receivers. J Sol Energy Eng 2014;136:031013. doi:10.1115/1.4027261.

[4] Sarwar J, Georgakis G, LaChance R, Ozalp N. Description and characterization of an adjustable flux solar simulator for solar thermal, thermochemical and photovoltaic applications. Sol Energy 2014;100:179-94. doi:10.1016/j.solener.2013.12.008.

[5] Pabst C, Feckler G, Schmitz S, Smirnova O, Capuano R, Hirth P, et al. Experimental performance of an advanced metal volumetric air receiver for Solar Towers. Renew Energy 2017;106:91-8. doi:10.1016/J.RENENE.2017.01.016.

[6] Garcia P, Ferriere A, Bezian J-J. Codes for solar flux calculation dedicated to central receiver system applications: A comparative review. Sol Energy 2008;82:189-97. doi:10.1016/j.solener.2007.08.004.

[7] Leary PL, Hankins JD. User's guide for MIRVAL: a computer code for comparing designs of heliostat-receiver optics for central receiver solar power plants. 1979.

[8] Wendelin T. SolTRACE: A New Optical Modeling Tool for Concentrating Solar Optics. Sol Energy 2003:253-60. doi:10.1115/ISEC2003-44090.

[9] Blanco MJ, Amieva JM, Mancilla A. THE TONATIUH SOFTWARE DEVELOPMENT PROJECT: AN OPEN SOURCE APPROACH TO THE SIMULATION OF SOLAR CONCENTRATING SYSTEMS. ASME Int. Mech. Eng. Congr. Expo., Orlando, Florida, USA: 2005, p. 1-8.

[10] Belhomme B, Pitz-Paal R, Schwarzbözl P, Ulmer S. A New Fast Ray Tracing Tool for HighPrecision Simulation of Heliostat Fields. J Sol Energy Eng 2009;131:031002. doi:10.1115/1.3139139.

[11] Roccia JP, Piaud B, Coustet C, Caliot C, Guillot E, Flamant G, et al. SOLFAST, a ray-tracing monte-carlo software for solar concentrating facilities. J Phys Conf Ser 2012;369. doi:10.1088/1742-6596/369/1/012029. 
[12] Garcia P, Ferriere A, Bezian JJ. Codes for solar flux calculation dedicated to central receiver system applications: A comparative review. Sol Energy 2008;82:189-97. doi:10.1016/j.solener.2007.08.004.

[13] Qiu Y, He Y-L, Li P, Du B-C. A comprehensive model for analysis of real-time optical performance of a solar power tower with a multi-tube cavity receiver. Appl Energy 2017;185:589-603. doi:10.1016/J.APENERGY.2016.10.128.

[14] Lipps FW, Vant-Hull LL. A cellwise method for the optimization of large central receiver systems. Sol Energy 1978;20:505-16. doi:10.1016/0038-092X(78)90067-1.

[15] Kistler BL. A User's Manual for DELSOL3: A Computer Code for Calculating the Optical Performance and Optimal System Design for Solar Thermal Central Receiver Plants. Albuquerque: 1986.

[16] Biggs F, Vittitoe CN. The Helios model for the optical behaviour of reflecting solar concentrators. Albuquerque, SAND76-0347: 1979.

[17] Collado FJ, Gómez A, Turégano JA. An analytic function for the flux density due to sunlight reflected from a heliostat.pdf. Sol Energy 1986;37:215-34.

[18] Monterreal R. Software developments for system analysis and optimization. Cologne (Germany): 2000.

[19] Schwarzbözl P, Pitz-Paal R, Schmitz M. Visual HFLCAL - A Software Tool for Layout and Optimisation of Heliostat Fields. SolarPACES, Berlin, Germany: SolarPACES; 2009.

[20] NREL. SolarPilot 2018:https://www.nrel.gov/csp/solarpilot.html.

[21] Sánchez-González A, Rodríguez-Sánchez MR, Santana D. Aiming factor to flatten the flux distribution on cylindrical receivers. Energy 2018;153. doi:10.1016/j.energy.2018.04.002.

[22] Rodríguez-Sánchez MR, Marugan-Cruz C, Acosta-lborra A, Santana D. Comparison of simplified heat transfer models and CFD simulations for molten salt external receiver. Appl Therm Eng 2014;73:991-1003. doi:10.1016/j.applthermaleng.2014.08.072.

[23] Chen D, Liu Y, Benito R, Stein W. CFD MODELLING OF THE RADIATION AND CONVECTION LOSSES IN THE MTSA RECEIVER 2006:1-6.

[24] Garbrecht O, Al-Sibai F, Kneer R, Wieghardt K. CFD-simulation of a new receiver design for a molten salt solar power tower. Sol Energy 2013;90:94-106. 
doi:10.1016/j.solener.2012.12.007.

[25] Colomer G, Chiva J, Lehmkuhl O, Oliva A. Advanced CFD\&amp;HT Numerical Modeling of Solar Tower Receivers. Energy Procedia 2014;49:50-9.

doi:10.1016/J.EGYPRO.2014.03.006.

[26] Wei M, Fan Y, Luo L, Flamant G. Fluid flow distribution optimization for minimizing the peak temperature of a tubular solar receiver. Energy 2015;91:663-77.

doi:10.1016/j.energy.2015.08.072.

[27] Colleoni A, Toutant A, Olalde G. Simulation of an innovative internal design of a plate solar receiver: Comparison between RANS and LES results. Sol Energy 2014;105:732-41. doi:10.1016/j.solener.2014.04.017.

[28] Yu Q, Wang Z, Xu E. Simulation and analysis of the central cavity receiver's performance of solar thermal power tower plant. Sol Energy 2012;86:164-74.

doi:10.1016/j.solener.2011.09.022.

[29] Fritsch A, Uhlig R, Marocco L, Frantz C, Flesch R, Hoffschmidt B. A comparison between transient CFD and FEM simulations of solar central receiver tubes using molten salt and liquid metals. Sol Energy 2017;155:259-66. doi:10.1016/J.SOLENER.2017.06.022.

[30] Cagnoli M, de la Calle A, Pye J, Savoldi L, Zanino R. A CFD-supported dynamic systemlevel model of a sodium-cooled billboard-type receiver for central tower CSP applications. Sol Energy 2019;177:576-94. doi:10.1016/J.SOLENER.2018.11.031.

[31] Falcone P. A handbook for solar central receiver design. Livermore, California: Sandia National Laboratories; 1986.

[32] Rodríguez-Sánchez MR, Soria-Verdugo A, Almendros-Ibáñez JA, Acosta-Iborra A, Santana D. Thermal design guidelines of solar power towers. Appl Therm Eng 2014;63:428-38. doi:10.1016/j.applthermaleng.2013.11.014.

[33] Rodríguez-Sánchez MR, Marugán-Cruz C, Acosta-Iborra A, Santana D. Thermomechanical modelling of solar central receivers: effect of incident solar flux resolution. Sol Energy 2018;165:43-54.

[34] Frantz C, Fritsch A, Uhlig R. ASTRID C- Advanced Solar Tubular Recelver Design: A powerful tool for receiver design and optimization. AIP Conf Proc 2017;1850. doi:10.1063/1.4984360. 
[35] Rodríguez-Sánchez MR, Sánchez-González A, Marugan-Cruz C, Santana D. Flow patterns of external solar receivers. Sol Energy 2015;122:940-53.

doi:10.1016/j.solener.2015.10.025.

[36] Sánchez-González A, Rodríguez-Sánchez MR, Santana D. Aiming strategy model based on allowable flux densities for molten salt central receivers. Sol Energy 2017;157. doi:10.1016/j.solener.2015.12.055.

[37] Ho CK. Software and Codes for Analysis of Concentrating Solar Power Technologies. Contract 2008. doi:10.2172/946571.

[38] Blair N, Dobos AP, Freeman J, Neises T, Wagner M, Ferguson T, et al. System Advisor Model (SAM): General description. Denver, NREL/TP-6A20-61019: 2014.

[39] Wagner MJ. Simulation and Predictive Performance Modeling of Utility-Scale Central Receiver System Power Plants. University of Wisconsin, Madison, 2008.

[40] Stoddard MC, Faas SE, Chiang CJ, Dirks J a. SOLERGY - A Computer Code for Calculating the Annual Energy from Central Receiver Power Plants 1987:153.

[41] Gertig C, Delgado A, Hidalgo C, Ron R. SoFiA - A Novel Simulation Tool for Central Receiver Systems. Energy Procedia 2014;49:1361-70. doi:10.1016/j.egypro.2014.03.145.

[42] Li L, Sun J, Li Y. Prospective fully-coupled multi-level analytical methodology for concentrated solar power plants: General modelling. Appl Therm Eng 2017;118:171-87. doi:10.1016/j.applthermaleng.2017.02.086.

[43] Radosevich LG. Final Report on the Power Production Phase of the 10MWe Solar Thermal Central Receiver Pilot Plant. Livermore, California: 1988. doi:SAN087-8022.

[44] Rodriguez-Sanchez MR, Sanchez-Gonzalez A, Santana D. Revised receiver efficiency of molten-salt power towers. Renew Sustain Energy Rev 2015;52. doi:10.1016/j.rser.2015.08.004.

[45] Sánchez-González A, Santana D. Solar flux distribution on central receivers: a projection method from analytic function. Renew Energy 2015;74:576-87.

[46] Sánchez-González A, Caliot C, Ferrière A, Santana D. Determination of heliostat canting errors via deterministic optimization. Sol Energy 2017;150:136-46. doi:10.1016/j.solener.2017.04.039. 